\title{
Optimization of Spectrophotometric and Fluorometric Assays Using Alternative Substrates for the High-Throughput Screening of Lipase Activity
}

\author{
Jun-Young Park, ${ }^{1}$ Jisu Ha, ${ }^{2}$ Yoonseok Choi, ${ }^{1}$ Pahn-Shick Chang $\mathbb{D}^{1,3,4,5}$ \\ and Kyung-Min Park $\mathbb{D}^{2,5}$ \\ ${ }^{1}$ Department of Agricultural Biotechnology, Seoul National University, Seoul 08826, Republic of Korea \\ ${ }^{2}$ Department of Food Science and Biotechnology, Wonkwang University, Iksan 54538, Republic of Korea \\ ${ }^{3}$ Research Institute of Agriculture and Life Sciences, Seoul National University, Seoul 08826, Republic of Korea \\ ${ }^{4}$ Center for Food and Bioconvergence, Seoul National University, Seoul 08826, Republic of Korea \\ ${ }^{5}$ Center for Agricultural Microorganism and Enzyme, Seoul National University, Seoul 08826, Republic of Korea \\ Correspondence should be addressed to Pahn-Shick Chang; pschang@snu.ac.kr and Kyung-Min Park; kmpark79@wku.ac.kr
}

Received 10 May 2021; Revised 6 July 2021; Accepted 20 July 2021; Published 28 July 2021

Academic Editor: Alina Barbulescu

Copyright (c) 2021 Jun-Young Park et al. This is an open access article distributed under the Creative Commons Attribution License, which permits unrestricted use, distribution, and reproduction in any medium, provided the original work is properly cited.

\begin{abstract}
The effects of reaction conditions on the spectrophotometric and fluorometric assays using alternative substrates ( $p$-nitrophenyl palmitate and 4-methylumbelliferyl oleate) were investigated to optimize them for the high-throughput screening of lipase activity from agricultural products. Four model lipases from Chromobacterium viscosum, Pseudomonas fluorescens, Sus scrofa pancreas, and wheat germ (Triticum aestivum) were allowed to hydrolyze the alternative substrates at different substrate concentrations (1-5 $\mathrm{mM})$, operating $\mathrm{pH}(5.0-8.0)$, and operating temperatures $\left(25-55^{\circ} \mathrm{C}\right)$. The results show that both the spectrophotometric and fluorometric assays worked well at the standard reaction conditions $\left(\mathrm{pH} 7.0\right.$ and $\left.30^{\circ} \mathrm{C}\right)$ for finding a typical lipase, although $\mathrm{pH}$ conditions should be considered to detect the catalytic activity of lipases, which are applicable to more acidic or alkaline $\mathrm{pH}$ circumstances. To validate the optimized conditions, the high-throughput screening of lipase activity was conducted using 17 domestic agricultural products. A pileus of Pleurotus eryngii showed the highest activity in both the spectrophotometric $(633.42 \mu \mathrm{U} / \mathrm{mg})$ and fluorometric $(101.77 \mu \mathrm{U} / \mathrm{mg})$ assays. The results of this research provide practical information for the highthroughput screening of lipases using alternative substrates on microplates.
\end{abstract}

\section{Introduction}

Lipases (i.e., triacylglycerol hydrolase, EC 3.1.1.3) are carboxylic ester hydrolases found in diverse organisms, including animals, plants, fungi, and bacteria that can catalyze the hydrolysis of triacylglycerols into diacylglycerols, monoacylglycerol, and free fatty acids [1]. These enzymes are highly soluble in aqueous phases, similar to other enzymes; however, their substrates are highly water-insoluble acylglycerol species, and consequently, lipases can efficiently catalyze hydrolysis at the interface between water and oil droplets [2]. Most lipases from eukaryotes precisely control the accessibility of their active site to their substrates by opening and closing their lid structure at oil/water interface $[3,4]$. Furthermore, lipases typically exhibit unique selectivities on their substrates, such as typoselectivity, regioselectivity, and stereoselectivity $[5,6]$, though a few lipases show promiscuous behavior toward their substrates [7]. Because of those attractive properties, lipases are being studied in the fields of selective hydrolysis for flavor/texture improvement $[8,9]$, esterification for the synthesis of structured lipids or functional compounds $[10,11]$, and other catalytic reactions. These versatile enzymes have been discovered and developed from various sources to have 
individual characteristics and stabilities suitable for the food, chemical, detergent, cosmetic, leather, diagnosis, and pharmaceutical industries [12]. Therefore, it is important to pursue the discovery of novel lipases with unique properties from natural sources.

The first requirement for the discovery of lipases is to establish a high-throughput methodology to rapidly and precisely determine their catalytic activity. Numerous methodologies are available for the detection of lipase activity [13]. Among them, chemical methodologies (e.g., titrimetric, spectroscopic, and chromatographic assays) that measure the appearance of hydrolytic reaction products are commonly used [14]. Ironically, using original acylglycerol species as substrates for lipase reactions is a hindrance to high-throughput screening because most of the relevant methodologies are complicated or laborious due to their high lipophilicity and analytical difficulty of their products. Those reactions have to be conducted in a complex phase such as an emulsion or reverse micelle to adequately disperse the lipophilic substrates in the aqueous phase, which demands a number of ingredients to prepare a reaction medium $[15,16]$. Those methods also require further steps and a long time to analyze the free fatty acids that are the reaction products. For that reason, previous studies have developed artificial alternative substrates such as $p$-nitrophenyl fatty acid esters, 4-methylumbelliferyl fatty acid esters, or other functionalized fatty acid derivatives [17, 18], which are relatively soluble in the aqueous phase. The products liberated from the alternative substrates during lipase-catalyzed hydrolysis contain specific compounds that can be detected by spectrophotometry or fluorometry, which allows the reaction progress to be analyzed conveniently on microplates and is thus appropriate for high-throughput screening. Unfortunately, however, studies to find novel lipases have been conducted sporadically, and the detailed screening conditions (e.g., buffer, $\mathrm{pH}$, temperature, and enzyme-substrate ratio) are highly inconsistent. These methodologies need to be optimized according to the type of substrate and lipase to validate whether they can be reliably reproduced with lipases from a variety of natural sources.

In this study, to establish an optimized enzymatic platform for the high-throughput screening of lipase from agricultural sources, we constructed spectrophotometric and fluorometric assays based on two alternative substrates ( $p$ nitrophenyl palmitate ( $p$-NPP) [19] and 4-methylumbelliferyl oleate (4-MUO) [20]) and investigated the effects of major reaction conditions ( $\mathrm{pH}$ and temperature) on both assays using four commercial lipases from different origins (lipase from Chromobacterium viscosum (CVL), lipase from Pseudomonas fluorescens (PFL), lipase from porcine (Sus scrofa) pancreas (PPL), and lipase from wheat germ (Triticum aestivum) (WGL)). The reactions were tested on 96-well microplates at different $\mathrm{pH}$, temperature, enzyme concentration, and substrate concentration conditions, and their discrepancy was investigated. The lipase reactions using $p$-NPP and 4-MUO as substrates were monitored by spectrophotometric and fluorometric methodologies to detect $p$-nitrophenol and 4-methylumbelliferone, respectively. Furthermore, we validated the optimized conditions by applying them to high-throughput screening for lipase activity in crude protein extracts from domestic agricultural sources. The following results would provide practical information about high-throughput screening for lipases using alternative substrates on microplates.

\section{Materials and Methods}

2.1. Materials. The alternative substrates, $p$-NPP $(\geq 98 \%)$ and 4 -MUO ( $\geq 95 \%)$, were purchased from Sigma-Aldrich Co. (St. Louis, MO, USA). The reaction products, $p$-nitrophenol $(\geq 99 \%)$ and 4-methylumbelliferone $(\geq 98 \%)$, and commercial lipases, CVL $(\geq 2,500 \mathrm{U} / \mathrm{mg})$, PFL ( $\geq 20 \mathrm{U} / \mathrm{mg})$, PPL (100-650 U/mg), and WGL (5-15 U/mg, triacetin), were also purchased from Sigma-Aldrich Co. One unit is defined as the amount of enzyme that will release $1.0 \mu \mathrm{mol}$ of fatty acids from the substrate per min at each condition given in the manufacturer's instructions. All other chemicals were of analytical reagent grade and were used after filtration through a membrane filter $(0.45 \mu \mathrm{m})$. The 17 domestic agricultural products (cereals, vegetables, mushrooms, nuts, and seeds) were purchased from local markets. The Costar ${ }^{\circledR}$ 96-well microplates (black wall, clear bottom) used for the fluorometric analyses were purchased from Corning Co. (Corning, NY, USA). The JetBiofil ${ }^{\circledR}$ 96-well microplates (clear wall and clear bottom) used for the spectrophotometric analyses were purchased from Guangzhou Jet Biofiltration Co. (Guangzhou, China).

2.2. Enzyme and Substrate Sample Preparation. Four lipase stock solutions (CVL, PFL, PPL, and WGL) were prepared by dissolving $10 \mathrm{mg}$ of the solid enzyme directly into $1 \mathrm{~mL}$ of $50 \mathrm{mM}$ Tris- $\mathrm{HCl}$ buffer at room temperature. The PPL stock solution was subsequently centrifuged at $5,000 \times \mathrm{g}$ for $10 \mathrm{~min}$ to remove a large amount of insoluble material before the enzyme assay [21]. All the lipase stock solutions were stored at $4^{\circ} \mathrm{C}$ until use. The substrate stock solutions ( $p$-NPP and 4MUO) were prepared as previously described [21, 22] with slight modifications. In brief, the $p$-NPP stock solution $(5.00 \mathrm{mM})$ was prepared by dissolving $62.29 \mathrm{mg}$ of $p$-NPP into $33 \mathrm{~mL}$ of distilled water with $330.0 \mathrm{mg}$ of Triton X-100 and $11.0 \mathrm{mg}$ of sodium dodecyl sulfate. The solution was heated at $65^{\circ} \mathrm{C}$ for $20 \mathrm{~min}$ with magnetic stirring, cooled to room temperature, and stored at $4^{\circ} \mathrm{C}$ until use. The 4 -MUO stock solution $(50 \mathrm{mM})$ was prepared by dissolving $25 \mathrm{mg}$ of 4-MUO into $1.1348 \mathrm{~mL}$ of dimethyl sulfoxide (DMSO) with vortexing. The $4-\mathrm{MUO}$ stock solution was stored at $-18^{\circ} \mathrm{C}$ until use. All the substrate stock solutions were dissolved in $50 \mathrm{mM}$ Tris- $\mathrm{HCl}$ buffer to give the specific concentration needed for each experiment.

2.3. Lipase Activity Assay Using $p-N P P$ as a Substrate. The lipase assay using $p$-NPP as a substrate was established based on the spectrophotometric methodology as previously described [22] with slight modifications. Substrate solution $(0.1 \mathrm{~mL})$ at a specific concentration was added to a 96-well microplate and preincubated in a microplate reader (SpectraMax iD3 multimode microplate reader, Molecular 
Devices, San Jose, CA, USA) for $5 \mathrm{~min}$. Then, lipase-catalyzed hydrolysis was initiated by adding the enzyme solution $(0.1 \mathrm{~mL})$ to the substrate solution. The absorbance of each well at $410 \mathrm{~nm}\left(\varepsilon=18.3 \mathrm{mM}^{-1} \mathrm{~cm}^{-1}\right)$ was monitored over the reaction time to quantitate the amount of $p$-nitrophenol liberated from the $p$-NPP during the hydrolysis. A calibration curve of $p$-nitrophenol concentration versus the absorption unit (AU) was plotted using a p-nitrophenol standard compound (Supplementary Figure S1). One unit of lipase catalytic activity was defined as the amount of enzyme liberating $1 \mu \mathrm{mol}$ of $p$-nitrophenol per minute. Hyperbolic nonlinear regression curve fitting for the production of $p$ nitrophenol against the reaction time was performed using SigmaPlot software (ver. 12.5, Systat Software Co., San Jose, CA, USA). The final concentration of the liberated $p$ nitrophenol was determined from each reaction curve, and the differences between initial concentration and final concentration of the product were converted into the values of the average rate of change (i.e., $\mathrm{U} / \mathrm{mL}$ per $60 \mathrm{~min}$ ) as follows:

$$
\text { Catalytic activity }(\mu \mathrm{mol} / \mathrm{min} / \mathrm{mL})=\frac{[P]_{f}-[P]_{i}}{t},
$$

where $[P]_{i}$ and $[P]_{f}$ are the initial and final concentrations of $p$-nitrophenol in each well, respectively, and $t$ is the reaction time (in this case, $60 \mathrm{~min}$ ).

2.4. Lipase Activity Assay Using 4-MUO as a Substrate. The lipase assay using 4-MUO as a substrate was established based on the fluorometric methodology as previously described [21] with slight modifications. Substrate solution $(0.1 \mathrm{~mL})$ at a specific concentration was added to a 96-well microplate and preincubated in a microplate reader for $5 \mathrm{~min}$. Then, lipase-catalyzed hydrolysis was initiated by adding the enzyme solution $(0.1 \mathrm{~mL})$ to the substrate solution. The fluorescence of 4-methylumbelliferone liberated during hydrolysis was detected at an excitation wavelength of $320 \mathrm{~nm}$ and an emission wavelength of $455 \mathrm{~nm}$ over the reaction time. The fluorescence data were acquired in bottom-reading mode and PMT low measurement. The excitation and emission slit widths were set at 9 and $15 \mathrm{~nm}$, respectively. A calibration curve of 4-methylumbelliferone concentration versus the relative fluorescence unit (RFU) was plotted using 4-methylumbelliferone standard compound (Supplementary Figure S2). One unit of catalytic activity of lipase was defined as the amount of enzyme liberating $1 \mu \mathrm{mol}$ of 4 -methylumbelliferone per minute. Hyperbolic nonlinear regression curve fitting of the production of 4-methylumbelliferone against the reaction time was conducted as aforementioned. The final concentration of the liberated 4-methylumbelliferone was determined from each reaction curve, and the differences between initial concentration and final concentration of the product were converted into the values of the average rate of change as follows:

$$
\text { Catalytic activity }(\mu \mathrm{mol} / \mathrm{min} / \mathrm{mL})=\frac{[M]_{f}-[M]_{i}}{t},
$$

where $[M]_{i}$ and $[M]_{f}$ are the initial and final concentrations of 4-methylumbelliferone in each well, respectively, and $t$ is the reaction time (in this case, $60 \mathrm{~min}$ ).

2.5. Crude Protein Extraction and Lipase Activity Screening. Crude protein extraction from the domestic agricultural products was conducted using a Pierce ${ }^{\mathrm{TM}}$ Plant Total Protein Extraction Kit (Thermo Fisher Scientific Co., Rockford, IL, USA) according to the manufacturer's instructions with slight modifications. In brief, a $100 \mathrm{mg}$ sample of each domestic agricultural product was prepared and placed in the filter. For plant leaves, the samples were folded into a small size and punched with a pipette tip about 60 times. For seeds and stems, the samples were cut into small pieces and minced about 60 times using a plastic rod. One hundred microliters of native lysis buffer were added to the filter, and the samples were ground using a plastic rod with twisting force about 60 times. Then, the filter was covered and incubated on ice for $5 \mathrm{~min}$ before centrifugation at $16,000 \times \mathrm{g}$ for $5 \mathrm{~min}$. The supernatant containing the total proteins was used for the lipase activity screening, and the spectrophotometric and fluorometric assays were conducted as aforementioned.

2.6. Statistical Analysis. All the reactions were conducted in triplicate under the same conditions. Statistical analyses were performed using SPSS software (ver. 25.0, IBM Co., Armonk, NY, USA). The data were subjected to one-way analysis of variance (ANOVA), and statistical significance between data groups was validated using Duncan's multiple range test $(p<0.05)$.

\section{Results and Discussion}

\subsection{Optimization of the Lipase Assay Using p-NPP as an Alternative Substrate}

\subsubsection{Effects of Substrate Concentration on the Lipase Assay} Using $p-N P P$. Lipase activity is highly affected by physicochemical conditions such as the enzyme-substrate molar ratio, $\mathrm{pH}$, temperature, ionic strength, and additives [23]. Lipases could exhibit different catalytic activity and especially substrate specificity depending on to the reaction conditions. Hence, in this study, we investigated the effects of three major reaction conditions (substrate concentration, $\mathrm{pH}$, and temperature) and scrutinized the practical results of spectrophotometric and fluorometric lipase assays conducted using alternative substrates. The substrate molar concentration is the most critical parameter in determining the initial velocity and kinetics of an enzyme reaction. At a specific enzyme concentration, the reaction rate is relatively slow in the range of low substrate concentration, whereas it gradually increases with the substrate concentration until substrate saturation point is reached [24]. Thus, highthroughput screening for catalytic activity should consider whether the target substrate added to the reaction medium is enough to react with the target enzyme. To investigate the effects of substrate concentration, we conducted lipase- 
catalyzed hydrolysis of $p$-NPP at different initial concentrations $(1.0-5.0 \mathrm{mM})$ using otherwise standard conditions $\left(\mathrm{pH} 7.0\right.$ and $\left.30^{\circ} \mathrm{C}\right)$ for $60 \mathrm{~min}$ (Figure 1). The reaction progress curves of all lipases showed constant linearity at the early stage of progress (data not shown), and the final concentrations of the liberated $p$-nitrophenol were determined from the nonlinear regression curves of $p$-nitrophenol concentrations versus reaction time. As the substrate concentration increased, the catalytic activity of the lipases increased gradually, peaked at $2.0-3.0 \mathrm{mM} p$-NPP, and then decreased slightly. Among them, WGL showed the highest catalytic activity $(1.38 \pm 0.10 \mathrm{U} / \mathrm{mL}, p=0.000-0.002)$ at $3 \mathrm{mM}$ substrate condition. Except PFL $(0.55 \pm 0.02 \mathrm{U} / \mathrm{mL}$ at $2 \mathrm{mM} p$-NPP), other lipases similarly showed the optimal reaction at $3 \mathrm{mM}$ substrate condition. The detailed catalytic characteristics of the model lipases differ from one other; however, our results indicate that the present range of $p$ NPP concentration is enough to find various lipases with adequate catalytic activity in a small-scale reaction on microplates. Notably, there was a reduction of lipase activity at higher substrate concentrations, a phenomenon called substrate inhibition that is generally observed in lipasecatalyzed hydrolysis. Excessive amounts of substrate compared with enzyme cause unintended competition with itself in a form of competitive inhibition [25]. Furthermore, the water solubility of $p$-NPP is relatively low due to its fatty acid moiety, so surfactants such as Triton X-100 and sodium dodecyl sulfate had to be used to completely solubilize $p$ NPP in the aqueous phase (3.2.), although these molecules could have a negative effect on enzyme protein. Therefore, the high-throughput methodology using $p$-NPP as an alternative substrate basically considers whether the substrate concentration is appropriate to mitigate the negative effect on the lipase activity and consequently detect any level of lipase activity efficiently.

\subsubsection{Effects of Operating $p H$ on the Lipase Assay Using p-} NPP. The $\mathrm{pH}$ value of the reaction medium (i.e., operating $\mathrm{pH}$ ) is also important to screen the lipase activity from natural sources. The degree of acidity or basicity can affect the catalytic activity of enzymes by altering the ionization state of an enzyme's active site, even worse, causing an irreversible change in the protein structure by disrupting internal ionic bonds [26]. In other words, enzymes only work in a particular $\mathrm{pH}$ range typically showing a bellshaped plot of the $\mathrm{pH}$ value versus catalytic activity. Until now, lipases with various optimum $\mathrm{pH}$ from acidic to basic have been discovered and developed to serve industrial purpose. Hence, a high-throughput methodology to detect lipase activity should be uninterrupted by any $\mathrm{pH}$ value. To investigate the effects of operating $\mathrm{pH}$ on the lipase-catalyzed hydrolysis of $p$-NPP, reactions were conducted in a typical $\mathrm{pH}$ range $(5.0-8.0)$ at $30^{\circ} \mathrm{C}$ for $60 \mathrm{~min}$ (Figure 2), and final concentrations of liberated $p$-nitrophenol were compared. All the lipases except WGL showed the highest catalytic activity (CVL, $1.32 \pm 0.16 \mathrm{U} / \mathrm{mL} ; \mathrm{PFL}, 0.50 \pm 0.02 \mathrm{U} /$ $\mathrm{mL}$; PPL, $0.37 \pm 0.01 \mathrm{U} / \mathrm{mL}$ ) at $\mathrm{pH} 7.0$ than at mild acidic $\mathrm{pH}$ 5.0-6.0, and WGL showed a constant activity at $\mathrm{pH} 6.0-8.0$

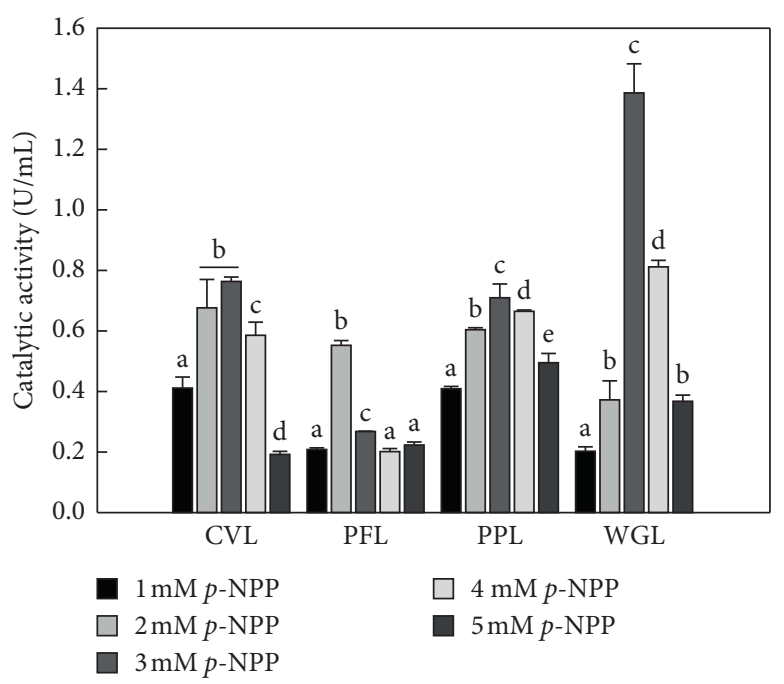

FIGURE 1: Effects of substrate ( $p$-nitrophenyl palmitate, $p$-NPP) concentration on the catalytic activity of lipases. The substrate concentration was in the range of $1-5 \mathrm{mM}$. Error bars indicate the standard error of the mean. Superscripts $(a-e)$ above the bars denote significant differences in catalytic activity $(p<0.05$, Duncan's multiple range test on ANOVA). CVL, Chromobacterium viscosum lipase $(0.01 \mathrm{mg} / \mathrm{mL})$; PFL, Pseudomonas fluorescens lipase $(0.001 \mathrm{mg} / \mathrm{mL})$; PPL, porcine (Sus scrofa) pancreatic lipase $(10 \mathrm{mg} /$ $\mathrm{mL})$; WGL, wheat germ (Triticum aestivum) lipase $(1 \mathrm{mg} / \mathrm{mL})$.

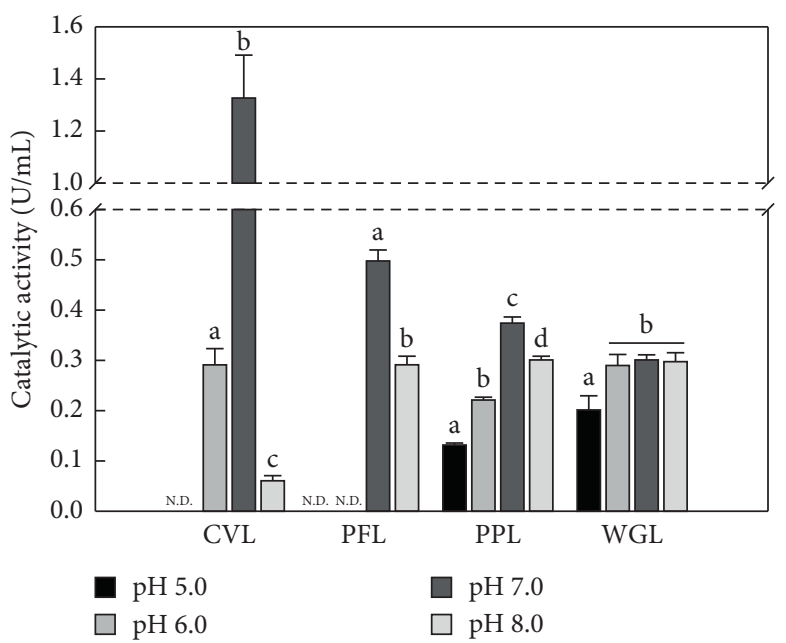

FIgURE 2: Effects of operating $\mathrm{pH}$ on the catalytic activity of lipases against $p$-nitrophenyl palmitate as a substrate. The operating $\mathrm{pH}$ was in the range of 5.0-8.0. Error bars indicate the standard error of the mean. Superscripts $(a-d)$ above the bars denote significant differences in catalytic activity $(p<0.05$, Duncan's multiple range test on ANOVA). CVL, Chromobacterium viscosum lipase $(0.01 \mathrm{mg} / \mathrm{mL})$; PFL, Pseudomonas fluorescens lipase $(0.001 \mathrm{mg} / \mathrm{mL})$; PPL, porcine (Sus scrofa) pancreatic lipase $(10 \mathrm{mg} / \mathrm{mL})$; WGL, wheat germ (Triticum aestivum) lipase $(1 \mathrm{mg} / \mathrm{mL})$; N.D, not detected.

( $p=0.908-0.978)$. In fact, the optimum $\mathrm{pH}$ of the four lipases was already known to be from neutral to slightly alkaline [27-30], and our results confirm that $p$-NPP can be used as the alternative substrate to detect the lipase activity at appropriate $\mathrm{pH}$ conditions. However, notably, the 
dissociation constant (pKa) of p-nitrophenol is 7.0-7.5 in aqueous solution at room temperature, and it gradually changes from yellow to colorless as the $\mathrm{pH}$ decreases to 5.4 $[31,32]$, which means the liberated products are difficult to detect in acidic conditions. Therefore, operating $\mathrm{pH}$ in the range of 7.0-8.0 is proper to screen typical lipase activity by using $p$-NPP, and it is also applicable to any alkaline $\mathrm{pH}$ to find the desired lipase with high activity or stability in strong alkaline environment.

\subsubsection{Effects of Operating Temperature on the Lipase Assay} Using $p$-NPP. Chemical reactions happen at specific rates at given conditions of substrate concentration and reaction temperature (i.e., operating temperature), and those reaction rates depend on the operating temperature according to the Arrhenius equation [24]. The hydrolysis of ester bonds catalyzed by lipase is also significantly affected by the operating temperature, and lipase assays therefore need the proper temperature to trigger and sustain a catalytic reaction. Furthermore, an enzyme can easily be inactivated at a high temperature because enzymes are protein macromolecules susceptible to thermal damage. Thus, a highthroughput methodology for detecting enzymes should maintain an appropriate operating temperature. To investigate the effects of operating temperature on the lipasecatalyzed hydrolysis of $p$-NPP, we conducted reactions in a typical temperature range for lipase reactions $\left(25-55^{\circ} \mathrm{C}\right)$ at $\mathrm{pH} 7.0$ for $60 \mathrm{~min}$ (Figure 3) and compared the final concentrations of liberated $p$-nitrophenol. The lipase activity at certain levels was successfully detected in all reaction conditions, and the highest catalytic activity occurred at $30-40^{\circ} \mathrm{C}$, which is near the optimum temperatures of four lipases $\left(30-50^{\circ} \mathrm{C}\right)[27-30]$. Among them, CVL showed the highest catalytic activity $(2.48 \pm 0.15 \mathrm{U} / \mathrm{mL}, p=0.000)$ at $30^{\circ} \mathrm{C}$. Therefore, operating temperatures in the range of $30-40^{\circ} \mathrm{C}$ are appropriate when screening for typical lipase activity using $p$-NPP without any interruption of catalytic activity, though a broad range of operating temperatures is also applied to find lipases specialized to specific temperature ranges from the small-scale reaction on microplates. Additionally, $p$-NPP is a highly stable compound at moderately high temperatures, which implies that a highthroughput methodology using $p$-NPP as the substrate could be applicable for finding thermostable lipases with high activity or stability at higher than usual temperatures.

\subsection{Optimization of the Lipase Assay Using 4-MUO as an Alternative Substrate}

3.2.1. Effects of Substrate Concentration on the Lipase Assay Using 4-MUO. Crude protein extracts of natural sources generally contain large amounts of chemical compounds such as phytochemicals, fatty acids, inorganic materials, and other proteins [33]. Compounds with noticeable color or fluorescence can interfere with the detection of catalytic activity of the target enzymes in the crude protein extract by directly inhibiting those enzymes or indirectly confusing the reaction outcomes. For that reason, more than a single

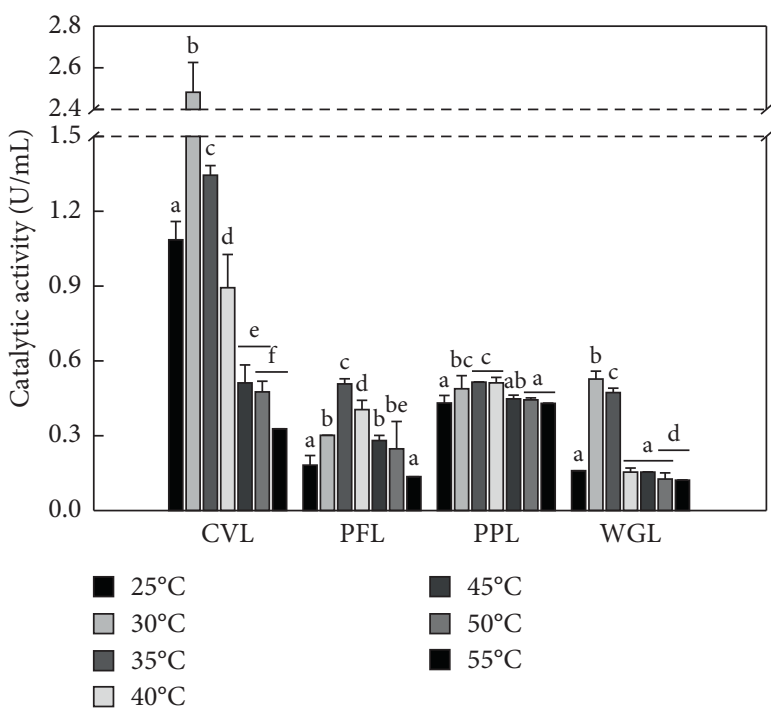

FIGURE 3: Effects of operating temperature on the catalytic activity of lipases against $p$-nitrophenyl palmitate as a substrate. The operating temperature was in the range of $25-55^{\circ} \mathrm{C}$. Error bars indicate the standard error of the mean. Superscripts $(a-f)$ above the bars denote significant differences in catalytic activity $(p<0.05$, Duncan's multiple range test on ANOVA). CVL, Chromobacterium viscosum lipase $(0.01 \mathrm{mg} / \mathrm{mL})$; PFL, Pseudomonas fluorescens lipase (0.001 mg/mL); PPL, porcine (Sus scrofa) pancreatic lipase (10 mg/ $\mathrm{mL}$ ); WGL, wheat germ (Triticum aestivum) lipase $(1 \mathrm{mg} / \mathrm{mL})$.

substrate should be used for high-throughput screening to discover novel lipases from natural sources. In this study, we also investigated the use of 4-MUO as an alternative substrate for high-throughput screening for lipase activity and optimized this fluorometric methodology, which detects light emissions (i.e., fluorescence) from the products absorbing excitation light at a specific wavelength. Upon lipase-catalyzed hydrolysis of the ester bond, 4-MUO produces 4-methylumbelliferone, which emits fluorescence at $445-455 \mathrm{~nm}$ wavelength when it is excited by light at 320-390 nm wavelength [20,34].

First of all, to investigate the effects of substrate on the reaction, we tested lipase-catalyzed hydrolysis of 4-MUO at different initial concentrations $(1.0-5.0 \mathrm{mM})$ using standard conditions $\left(\mathrm{pH} 7.0\right.$ and $30^{\circ} \mathrm{C}$ ) for $60 \mathrm{~min}$ (Figure 4). The reaction progress curves of all lipases showed constant linearity at the early stage of progress (data not shown), and the final concentrations of the products were determined from each nonlinear regression curve of 4-methylumbelliferone concentration versus reaction time. The catalytic activity of PPL gradually increased, peaked $(0.31 \pm 0.01 \mathrm{U} / \mathrm{mL})$ at $3.0 \mathrm{mM} 4-\mathrm{MUO}$, and decreased as the substrate concentration continued to increase, as shown in the $p$-NPP reaction. In the case of PFL and CVL, a slight tendency towards reduction in catalytic activity (i.e., substrate inhibition) was shown, whereas WGL showed a slight tendency to increase in catalytic activity. Notably, the molar concentrations of PFL and CVL used for the reaction with 4MUO as a substrate were relatively lower than those used for the reaction with $p$-NPP. We found that the catalytic activity of PFL and CVL was consistently higher than that of PPL 


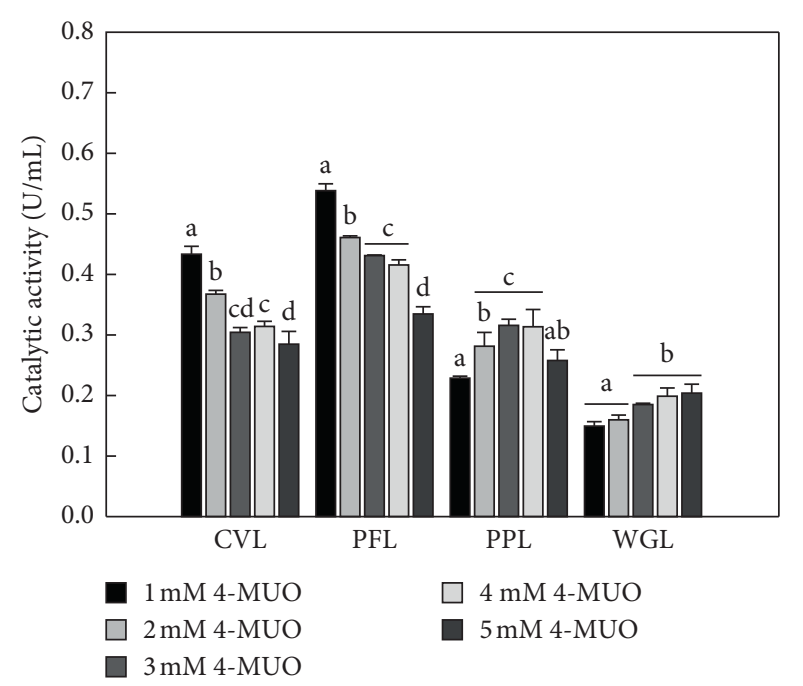

FIgURE 4: Effects of substrate (4-methylumbelliferyl oleate, 4MUO) concentration on the catalytic activity of lipases. The substrate concentration was in the range of 1-5 mM. Error bars indicate the standard error of the mean. Superscripts $(a-d)$ above the bars denote significant differences in catalytic activity $(p<0.05$, Duncan's multiple range test on ANOVA). CVL, Chromobacterium viscosum lipase $(0.1 \mu \mathrm{g} / \mathrm{mL})$; PFL, Pseudomonas fluorescens lipase $(0.1 \mu \mathrm{g} / \mathrm{mL})$; PPL, porcine (Sus scrofa) pancreatic lipase $(10 \mathrm{mg} /$ $\mathrm{mL}$ ); WGL, wheat germ (Triticum aestivum) lipase $(1 \mathrm{mg} / \mathrm{mL}$ ).

and WGL at the same enzyme concentrations (data not shown). In the fluorometric assay, an excessive amount of liberated fluorophore could generate a fluorescence value exceeding the sensitivity of the photomultiplier tube- (PMT-) based microplate reader. Therefore, a high-throughput methodology using 4-MUO as an alternative substrate should ensure that the substrate and enzyme concentrations are appropriate to detect any level of lipase activity precisely. Additionally, the presence of organic solvent DMSO for dissolving 4-MUO efficiently could have negatively affected the catalytic activity of the lipase; however, the actual amount of DMSO in the aqueous reaction medium $(<50 \%$ $(\mathrm{v} / \mathrm{v}))$ was not sufficient to lower the catalytic activity of lipase [35].

3.2.2. Effects of Operating $p H$ on the Lipase Assay Using 4$M U O$. The effects of the operating $\mathrm{pH}$ on the lipase-catalyzed hydrolysis of 4-MUO were investigated in a typical $\mathrm{pH}$ range (5.0-8.0) at $30^{\circ} \mathrm{C}$ for $60 \mathrm{~min}$ (Figure 5). All the lipases except WGL showed the highest catalytic activity (CVL, $0.60 \pm 0.01 \mathrm{U} / \mathrm{mL} ; \mathrm{PFL}, 0.41 \pm 0.05 \mathrm{U} / \mathrm{mL} ; \mathrm{PPL}, 0.37 \pm 0.01 \mathrm{U} /$ $\mathrm{mL}$ ) at $\mathrm{pH} 7.0$, exhibiting typical bell-shaped plots of $\mathrm{pH}$ value versus catalytic activity. Those results correspond with those from the spectrophotometric assay, indicating that the catalytic characteristics of each lipase with regard to operating $\mathrm{pH}$ conditions were expressed in the fluorometric assay without any external interference. Furthermore, 4-methylumbelliferone, which is the fluorescent product of the lipasecatalyzed hydrolysis of 4-MUO, is highly stable at acidic or alkaline $\mathrm{pH}$ circumstances, and lipase activity was

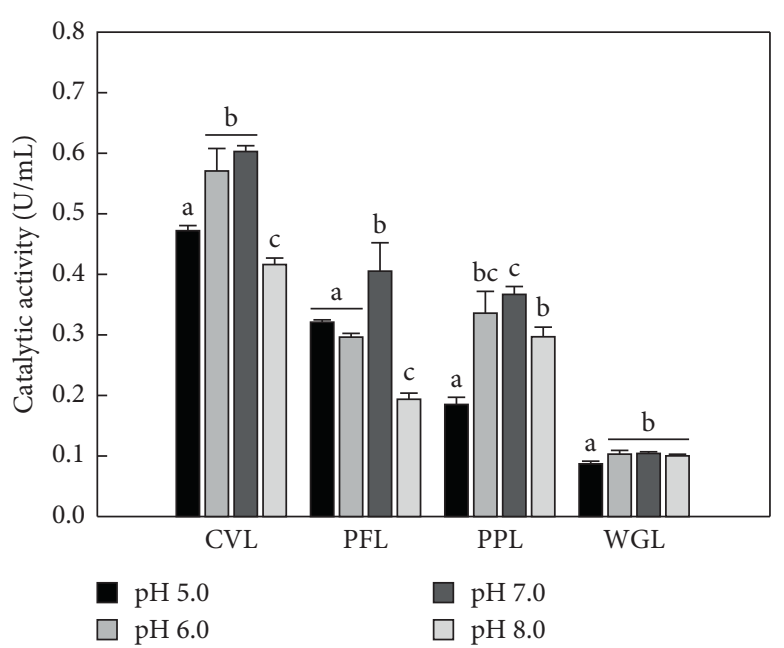

Figure 5: Effects of operating $\mathrm{pH}$ on the catalytic activity of lipases against 4-methylumbelliferyl oleate as a substrate. The operating $\mathrm{pH}$ was in the range of 5.0-8.0. Error bars indicate the standard error of the mean. Superscripts $(\mathrm{a}-\mathrm{c})$ above the bars denote significant differences in catalytic activity $(p<0.05$, Duncan's multiple range test on ANOVA). CVL, Chromobacterium viscosum lipase $(0.1 \mu \mathrm{g} / \mathrm{mL}) ; \mathrm{PFL}$, Pseudomonas fluorescens lipase $(0.1 \mu \mathrm{g} / \mathrm{mL}) ; \mathrm{PPL}$, porcine (Sus scrofa) pancreatic lipase $(10 \mathrm{mg} / \mathrm{mL})$; WGL, wheat germ (Triticum aestivum) lipase $(1 \mathrm{mg} / \mathrm{mL})$.

successfully detected in all reaction conditions. These results indicated that a high-throughput methodology using 4MUO as an alternative substrate could detect lipase activity in a broad range of $\mathrm{pH}$ conditions, in contrast to the spectrophotometric assay. On the other hand, a previous report on 4-methylumbelliferone showed that its maximum excitation and emission wavelengths $\left(\lambda_{\max }\right)$ could be affected by changes in $\mathrm{pH}$ and the addition of organic solvents $[20,36]$. This point should be especially considered when using 4-MUO as an alternative substrate for highthroughput screening of lipase activity; however, no critical change occurs in the fluorescence until the $\mathrm{pH}$ conditions become extreme. Therefore, an operating $\mathrm{pH}$ in the range of $7.0-8.0$ is appropriate for screening typical lipase activity using 4-MUO, and the excitation and emission conditions should be adjusted to detect the catalytic activity of lipase in more acidic or alkaline $\mathrm{pH}$ circumstances.

3.2.3. Effects of Operating Temperature on the Lipase Assay Using 4-MUO. The effects of operating temperature on the lipase-catalyzed hydrolysis of 4-MUO were investigated in a typical temperature range $\left(25-55^{\circ} \mathrm{C}\right)$ at $\mathrm{pH} 7.0$ for $60 \mathrm{~min}$ (Figure 6). The catalytic activity of each lipase was successfully detected in all temperature conditions, and the highest catalytic activity was shown at $30-40^{\circ} \mathrm{C}$, corresponding to the results from the spectrophotometric assay. Among them, PPL showed the highest catalytic activity $(0.49 \pm 0.02 \mathrm{U} / \mathrm{mL})$ at $35^{\circ} \mathrm{C}$, which is near the body temperature. High operating temperature had no significant effect in the detection of the reaction product or the stability of 4-MUO during hydrolysis. Therefore, the present operating temperature range is sufficient to find various lipases in 


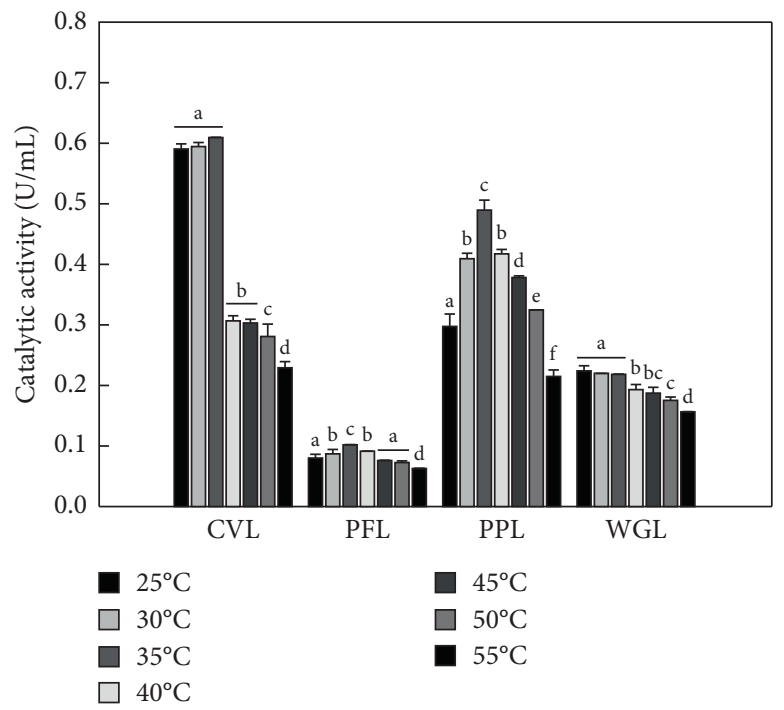

FIGURE 6: Effects of operating temperature on the catalytic activity of lipases against 4-methylumbelliferyl oleate as a substrate. The operating temperature was in the range of $25-55^{\circ} \mathrm{C}$. Error bars indicate the standard error of the mean. Superscripts (a-f) above the bars denote significant differences in catalytic activity $(p<0.05$, Duncan's multiple range test on ANOVA). CVL, Chromobacterium viscosum lipase $(0.1 \mu \mathrm{g} / \mathrm{mL}) ;$ PFL, Pseudomonas fluorescens lipase $(0.1 \mu \mathrm{g} / \mathrm{mL})$; PPL, porcine (Sus scrofa) pancreatic lipase $(10 \mathrm{mg} / \mathrm{mL})$; WGL, wheat germ (Triticum aestivum) lipase $(1 \mathrm{mg} / \mathrm{mL})$.

small-scale reactions with 4-MUO on microplates without any interruption. Of course, an operating temperature in the range of $30-40^{\circ} \mathrm{C}$ is generally proper for screening typical lipase activity because most lipases have optimum temperatures ranging from 30 to $50^{\circ} \mathrm{C}$. Overall, the effects of three major reaction conditions, which are key influence factors for the high-throughput screening of lipase activity, were comprehensively investigated and optimized using $p$ NPP and 4-MUO as alternative substrates. Based on those results, we conducted high-throughput screening of lipase activity from domestic agricultural products to validate whether our methodology could be uniformly reproduced with a variety of natural lipase sources.

\subsection{High-Throughput Screening of Lipase Activity from Do-} mestic Agricultural Products. Crude protein extracts from 17 agricultural products were screened for lipase activity using spectrophotometric and fluorometric assays simultaneously at optimized conditions. Domestic agricultural products containing more than $10.0 \mathrm{~g}$ of protein and $1.0 \mathrm{~g}$ of lipids were selected from the $9^{\text {th }}$ Korea National Standard Food Composition Table (Republic of Korea): 4 kinds of mushrooms (Lentinula, Agaricus, Hericium, and Pleurotus sp.), 5 kinds of vegetables (Glycine, Allium, Cucurbita, Capsicum, and Brassica sp.), 5 kinds of cereals (Coix, Fagopyrum, Amaranthus, Sorghum, and Oryza sp.), 2 kinds of seeds (Capsicum and Helianthus sp.), and 1 kind of nut (Arachis sp.). The protein concentrations of the crude protein extracts were below $20 \mathrm{mg} / \mathrm{mL}$, and the catalytic activity $(\mu \mathrm{U} / \mathrm{mL})$ of each sample was determined as the difference between the initial and final concentrations of the liberated products derived from nonlinear regression curves of product concentration versus reaction time. Then, the specific activity was derived by dividing the catalytic activity by protein concentration. We used those curves to calculate the lipase activity to account for the background absorbance or fluorescence of other compounds in the crude protein extracts that show color or fluorescence. The reactions were conducted at $\mathrm{pH} 7.0$ and $30^{\circ} \mathrm{C}$ for $60 \mathrm{~min}$ using $3 \mathrm{mM} p$-NPP or 4-MUO. The overall lipase activity in the crude protein extracts of the 17 agricultural products is summarized in Tables 1 and 2. Among them, a pileus (i.e., the upper cap-shaped part) of Pleurotus eryngii (king oyster mushroom) showed the highest lipase activity in both the spectrophotometric $(633.42 \mu \mathrm{U} / \mathrm{mg})$ and fluorometric $(101.77 \mu \mathrm{U} / \mathrm{mg})$ assays. Except for one study that purified feruloyl esterase (EC 3.1.1.73) from P. eryngii, that species has not been mentioned as a source for lipases or esterases [37]. However, as the conspecific fungus Pleurotus ostreatus is known to have many lipase and carboxylesterase genes [38], $P$. eryngii could be considered as an excellent source of lipases based on our results. Finally, the tendency of both spectrophotometric and fluorometric results was analogous to each other, although several samples showed different absorbance or fluorescence backgrounds, which consequently affected the lipase activity detected in identical samples. Therefore, it is better to apply both spectrophotometric and fluorometric assays simultaneously when screening for lipase activity to acquire more precise results, especially when screening crude protein extracts.

In addition, $p$-NPP and 4-MUO used in this study are representative compounds among the various $p$-nitrophenyl and 4-methylumbelliferyl fatty acids that can be used as alternative substrates for lipase. These series of compounds generate the same products after hydrolysis of their ester bonds by lipase. However, the physicochemical properties of those compounds are quite different based on the lipophilic moiety (i.e., fatty acid chain length), which significantly affects both the reaction conditions and the catalytic activity of lipase. Most lipases have a similar mode of action to 
TABLE 1: Lipase activity in crude protein extracts from domestic agricultural products (spectrophotometric assay).

\begin{tabular}{|c|c|c|c|c|c|}
\hline Classification & Name & Specimen & Concentration $(\mathrm{mg} / \mathrm{mL})$ & Activity $(\mu \mathrm{U} / \mathrm{mL})$ & $\begin{array}{l}\text { Specific activity } \\
(\mu \mathrm{U} / \mathrm{mg} \text { protein) }\end{array}$ \\
\hline \multirow{6}{*}{ Mushrooms } & \multirow{2}{*}{ Shiitake mushroom (Lentinula edodes) } & Pileus & 6.0080 & 148.0607 & 24.6439 \\
\hline & & Stalk & 4.6380 & 73.5127 & 15.8501 \\
\hline & White mushroom (Agaricus bisporus) & Whole & 7.4760 & 801.3916 & 107.1952 \\
\hline & Lion's mane mushroom (Hericium erinaceus) & Whole & 4.5490 & 218.4672 & 48.0253 \\
\hline & \multirow{2}{*}{ King oyster mushroom (Pleurotus eryngii) } & Pileus & 5.1730 & 633.4164 & 379.4340 \\
\hline & & Stalk & 4.2960 & 379.4340 & 633.4164 \\
\hline \multirow{8}{*}{ Vegetables } & \multirow{2}{*}{ Soybean sprout (Glycine max) } & Cotyledon & 16.4810 & N.D & N.D \\
\hline & & Hypocotyl & 5.0780 & 272.3075 & 53.6249 \\
\hline & Onion (Allium cepa) & Whole & 4.4080 & 197.7594 & 44.8638 \\
\hline & Pumpkin (Cucurbita moschata) & Whole & 5.2280 & 955.6646 & 182.7974 \\
\hline & Chili pepper (Capsicum annuum) & Whole & 11.0353 & N.D. & N.D. \\
\hline & \multirow{3}{*}{ Broccoli (Brassica oleracea) } & Crown & 5.0830 & 1653.8623 & 325.3713 \\
\hline & & Stalk & 7.0280 & 912.8685 & 129.8902 \\
\hline & & Leaf & 13.0710 & 138.3971 & 10.5881 \\
\hline \multirow{5}{*}{ Cereals } & Job's tears (Coix lacryma-jobi) & Whole & 8.2480 & 634.6938 & 76.9512 \\
\hline & Buckwheat (Fagopyrum esculentum) & Whole & 9.2220 & 980.1688 & 106.2859 \\
\hline & Pigweed (Amaranthus sp.) & Whole & 4.4660 & 294.3958 & 65.9193 \\
\hline & Sorghum (Sorghum bicolor) & Whole & 4.0380 & 190.5117 & 47.1797 \\
\hline & Brown rice (Oryza sativa) & Whole & 5.2450 & 666.7909 & 127.1289 \\
\hline \multirow{3}{*}{ Nuts/seeds } & Chili pepper seed (Capsicum annuum) & Whole & 5.6420 & 1941.3555 & 344.0900 \\
\hline & Sunflower seed (Helianthus annuus) & Whole & 5.8240 & 768.2591 & 131.9126 \\
\hline & Peanut (Arachis hypogaea) & Whole & 5.4650 & 630.8974 & 115.4433 \\
\hline
\end{tabular}

N.D, not detected.

TABLE 2: Lipase activity in crude protein extracts from domestic agricultural products (fluorometric assay).

\begin{tabular}{|c|c|c|c|c|c|}
\hline Classification & Name & Specimen & $\begin{array}{l}\text { Concentration } \\
(\mathrm{mg} / \mathrm{mL})\end{array}$ & $\begin{array}{l}\text { Activity } \\
(\mu \mathrm{U} / \mathrm{mL})\end{array}$ & $\begin{array}{l}\text { Specific activity } \\
(\mu \mathrm{U} / \mathrm{mg} \text { protein })\end{array}$ \\
\hline \multirow{6}{*}{ Mushrooms } & \multirow{2}{*}{ Shiitake mushroom (Lentinula edodes) } & Pileus & 6.0080 & 78.7792 & 13.1124 \\
\hline & & Stalk & 4.6380 & 12.2526 & 2.6418 \\
\hline & White mushroom (Agaricus bisporus) & Whole & 7.4760 & 20.9502 & 2.8023 \\
\hline & Lion's mane mushroom (Hericium erinaceus) & Whole & 4.5490 & 275.7866 & 60.6258 \\
\hline & \multirow{2}{*}{ King oyster mushroom (Pleurotus eryngii) } & Pileus & 5.1730 & 526.4440 & 40.8223 \\
\hline & & Stalk & 4.2960 & 175.3725 & 101.7676 \\
\hline \multirow{8}{*}{ Vegetables } & \multirow{2}{*}{ Soybean sprout (Glycine max) } & Cotyledon & 16.4810 & 91.2425 & 5.5362 \\
\hline & & Hypocotyl & 5.0780 & 48.6468 & 9.5799 \\
\hline & Onion (Allium cepa) & Whole & 4.4080 & 33.1211 & 7.5139 \\
\hline & Pumpkin (Cucurbita moschata) & Whole & 5.2280 & 159.3122 & 30.4729 \\
\hline & Chili pepper (Capsicum annuum) & Whole & 11.0353 & 7.8445 & 0.7109 \\
\hline & \multirow{3}{*}{ Broccoli (Brassica oleracea) } & Crown & 5.0830 & 426.2458 & 83.8571 \\
\hline & & Stalk & 7.0280 & 168.1837 & 23.9305 \\
\hline & & Leaf & 13.0710 & 120.8350 & 9.2445 \\
\hline \multirow{5}{*}{ Cereals } & Job’s tears (Coix lacryma-jobi) & Whole & 8.2480 & 68.7360 & 8.3337 \\
\hline & Buckwheat (Fagopyrum esculentum) & Whole & 9.2220 & 206.0473 & 22.3430 \\
\hline & Pigweed (Amaranthus sp.) & Whole & 4.4660 & 73.7128 & 16.5053 \\
\hline & Sorghum (Sorghum bicolor) & Whole & 4.0380 & 40.7260 & 10.0857 \\
\hline & Brown rice (Oryza sativa) & Whole & 5.2450 & 105.8386 & 20.1790 \\
\hline \multirow{3}{*}{ Nuts/seeds } & Chili pepper seed (Capsicum annuum) & Whole & 5.6420 & 554.3091 & 98.2469 \\
\hline & Sunflower seed (Helianthus annuus) & Whole & 5.8240 & 7.3494 & 1.2619 \\
\hline & Peanut (Arachis hypogaea) & Whole & 5.4650 & 10.6436 & 1.9476 \\
\hline
\end{tabular}

hydrolyze triacylglycerols or other ester compounds based on a catalytic triad comprised of amino acid residues (SerAsp-His) like chymotrypsin, whereas regioselectivity or stereoselectivity could be expressed in different mechanisms derived from their structural differences and followed environmental changes in active site. Therefore, it needs to be 
considered and additionally optimized for the highthroughput screening conditions when using other substrates or finding stereoselective lipase in a further study.

\section{Conclusions}

In the present study, we comprehensively investigated the effects of reaction conditions on spectrophotometric and fluorometric assays of alternative substrates, and we optimized those conditions for the high-throughput screening of lipase activity in domestic agricultural products. Both assays using alternative substrates worked well at the standard reaction conditions $\left(\mathrm{pH} 7.0\right.$ and $30^{\circ} \mathrm{C}$ ) for finding a typical lipase. The $\mathrm{pH}$ conditions of the reactions should be especially considered to detect the catalytic activity of lipases in more acidic or alkaline $\mathrm{pH}$ circumstances. Hence, it is recommended to employ both spectrophotometric and fluorometric assays for the high-throughput screening of lipase activity. Moreover, we propose P. eryngii as a novel source of lipases for the first time. Our results could contribute to providing critical information pertaining to the discovery of lipases.

\section{Data Availability}

The data used to support the findings of this study are available from the corresponding author upon request.

\section{Conflicts of Interest}

The authors declare that they have no conflicts of interest.

\section{Authors' Contributions}

K.M.P. and P.S.C. conceived the study and designed the experiments. J.S.H. performed the experiments and analyzed the data. J.Y.P. and H.J.S. wrote the manuscript, and the first draft of the study was reviewed and revised by J.Y.P., H.J.S., C.Y.S., and K.M.P. All authors discussed the contents of the manuscript and approved the submission. Jun-Young Park and Jisa Ha contributed equally as first authors.

\section{Acknowledgments}

This study was supported by Wonkwang University in 2020 .

\section{Supplementary Materials}

Figure S1: calibration curves of $p$-nitrophenol ( $p$-NP) concentration versus absorption unit (AU) referring to the absorbance at $410 \mathrm{~nm}$. Figure S2: calibration curves of 4methylumbelliferone (4-MU) concentration versus relative fluorescence unit (RFU) referring to the emission fluorescence at $455 \mathrm{~nm}$. (Supplementary Materials)

\section{References}

[1] A. K. Singh and M. Mukhopadhyay, "Overview of fungal lipase: a review," Applied Biochemistry and Biotechnology, vol. 166, no. 2, pp. 486-520, 2012.
[2] P. K. Ghosh, R. K. Saxena, R. Gupta, R. P. Yadav, and S. Davidson, "Microbial lipases: production and applications," Science Progress, vol. 79, no. Pt 2, pp. 119-157, 1996.

[3] J. Polaina and A. L. Maccabe, "Molecular structure and function," in Industrial Enzymes: Structure, Function and Applications, pp. 263-281, Springer, Berlin, Germany, 2010.

[4] F. Secundo, G. Carrea, C. Tarabiono et al., "The lid is a structural and functional determinant of lipase activity and selectivity," Journal of Molecular Catalysis B: Enzymatic, vol. 39, no. 1-4, pp. 166-170, 2006.

[5] Y. Choi, J.-Y. Park, and P.-S. Chang, "Integral stereoselectivity of lipase based on the chromatographic resolution of enantiomeric/regioisomeric diacylglycerols," Journal of Agricultural and Food Chemistry, vol. 69, no. 1, pp. 325-331, 2021.

[6] E. Rogalska, C. Cudrey, F. Ferrato, and R. Verger, "Stereoselective hydrolysis of triglycerides by animal and microbial lipases," Chirality, vol. 5, no. 1, pp. 24-30, 1993.

[7] M. Kapoor and M. N. Gupta, "Lipase promiscuity and its biochemical applications," Process Biochemistry, vol. 47, no. 4, pp. 555-569, 2012.

[8] X. Duan, M. Xiang, L. Wang, Q. Yan, S. Yang, and Z. Jiang, "Biochemical characterization of a novel lipase from Malbranchea cinnamomea suitable for production of lipolyzed milkfat flavor and biodegradation of phthalate esters," Food Chemistry, vol. 297, Article ID 124925, 2019.

[9] S. Moayedallaie, M. Mirzaei, and J. Paterson, "Bread improvers: comparison of a range of lipases with a traditional emulsifier," Food Chemistry, vol. 122, no. 3, pp. 495-499, 2010.

[10] R. Morales-Medina, M. Munio, A. Guadix, and E. M. Guadix, "Development of an up-grading process to produce MLM structured lipids from sardine discards," Food Chemistry, vol. 228, pp. 634-642, 2017.

[11] J.-Y. Park, J. Myeong, Y. Choi et al., "Erythorbyl fatty acid ester as a multi-functional food emulsifier: enzymatic synthesis, chemical identification, and functional characterization of erythorbyl myristate," Food Chemistry, vol. 353, Article ID 129459, 2021.

[12] N. Sarmah, D. Revathi, G. Sheelu et al., "Recent advances on sources and industrial applications of lipases," Biotechnology Progress, vol. 34, no. 1, pp. 5-28, 2018.

[13] F. Beisson, A. Tiss, C. Rivière, and R. Verger, "Methods for lipase detection and assay: a critical review," European Journal of Lipid Science and Technology, vol. 102, no. 2, pp. 133-153, 2000.

[14] R. Gupta, P. Rathi, N. Gupta, and S. Bradoo, "Lipase assays for conventional and molecular screening: an overview," Biotechnology and Applied Biochemistry, vol. 37, no. 1, pp. 63-71, 2003.

[15] N. Gomes, C. Gonçalves, M. García-Román, J. A. Teixeira, and I. Belo, "Optimization of a colorimetric assay for yeast lipase activity in complex systems," Analytical Methods, vol. 3, no. 4, pp. 1008-1013, 2011.

[16] C. W. Kwon, K.-M. Park, S. J. Choi, and P.-S. Chang, “A reliable and reproducible method for the lipase assay in an AOT/isooctane reversed micellar system: modification of the copper-soap colorimetric method," Food Chemistry, vol. 182, pp. 236-241, 2015.

[17] J. Grognux, D. Wahler, E. Nyfeler, and J.-L. Reymond, "Universal chromogenic substrates for lipases and esterases," Tetrahedron: Asymmetry, vol. 15, no. 18, pp. 2981-2989, 2004.

[18] K. N. Ingenbosch, A. Rousek, D. S. Wunschik, and K. Hoffmann-Jacobsen, "A fluorescence-based activity assay for immobilized lipases in non-native media," Analytical Biochemistry, vol. 569, pp. 22-27, 2019. 
[19] N. Gupta, P. Rathi, and R. Gupta, "Simplified para-nitrophenyl palmitate assay for lipases and esterases," Analytical Biochemistry, vol. 311, no. 1, pp. 98-99, 2002.

[20] T. J. Jacks and H. W. Kircher, "Fluorometric assay for the hydrolytic activity of lipase using fatty acyl esters of 4-methylumbelliferone," Analytical Biochemistry, vol. 21, no. 2, pp. 279-285, 1967.

[21] J.-Y. Park, C. S. Kim, K.-M. Park, and P.-S. Chang, "Inhibitory characteristics of flavonol-3-O-glycosides from Polygonum aviculare L. (common knotgrass) against porcine pancreatic lipase," Scientific Reports, vol. 9, no. 1, p. 18080, 2019.

[22] J. Y. Park, K. M. Park, Y. Yoo et al., "Catalytic characteristics of asn-1(3) regioselective lipase from Cordyceps militaris," Biotechnology Progress, vol. 35, no. 2, p. e2744, 2019.

[23] J.-Y. Park, C. H. Kim, Y. Choi, K.-M. Park, and P.-S. Chang, "Catalytic characterization of heterodimeric linoleate $13 S$ lipoxygenase from black soybean (Glycine max (L.) Merr.)," Enzyme and Microbial Technology, vol. 139, Article ID 109595, 2020.

[24] P. K. Robinson, "Enzymes: principles and biotechnological applications," Essays in Biochemistry, vol. 59, pp. 1-41, 2015.

[25] M. C. Reed, A. Lieb, and H. F. Nijhout, "The biological significance of substrate inhibition: a mechanism with diverse functions," BioEssays, vol. 32, no. 5, pp. 422-429, 2010.

[26] C. B. Anfinsen, "Principles that govern the folding of protein chains," Science, vol. 181, no. 4096, pp. 223-230, 1973.

[27] M. R. Castellar, M. A. Taipa, and J. M. S. Cabral, "Kinetic and stability characterization of chromobacterium viscosum lipase and its comparison with Pseudomonas glumae lipase," Applied Biochemistry and Biotechnology, vol. 61, no. 3, pp. 299-314, 1997.

[28] L. Young Phil, C. Guk Hoon, and R. Joon Shick, "Purification and characterization of Pseudomonas fluorescens SIK W1 lipase expressed in Escherichia coli," Biochimica et Biophysica Acta (BBA)_Lipids and Lipid Metabolism, vol. 1169, no. 2, pp. 156-164, 1993.

[29] K. Bagi, L. M. Simon, and B. Szajáni, "Immobilization and characterization of porcine pancreas lipase," Enzyme and Microbial Technology, vol. 20, no. 7, pp. 531-535, 1997.

[30] V. S. Kapranchikov, N. A. Zherebtsov, and T. N. Popova, "Purification and characterization of lipase from wheat (Triticum aestivum L.) germ," Applied Biochemistry and Microbiology, vol. 40, no. 1, pp. 84-88, 2004.

[31] L. E. Janes, A. C. Löwendahl, and R. J. Kazlauskas, "Quantitative screening of hydrolase libraries using $\mathrm{pH}$ indicators: identifying active and enantioselective hydrolases," Chemistry-A European Journal, vol. 4, no. 11, pp. 2324-2331, 1998.

[32] G. N. Bowers Jr., R. B. McComb, R. G. Christensen, and R. Schaffer, "High-purity 4-nitrophenol: purification, characterization, and specifications for use as a spectrophotometric reference material," Clinical Chemistry, vol. 26, no. 6, pp. 724-729, 1980.

[33] S. Seth, D. Chakravorty, V. K. Dubey, and S. Patra, "An insight into plant lipase research-challenges encountered," Protein Expression and Purification, vol. 95, pp. 13-21, 2014.

[34] R. F. Chen, "Fluorescent $\mathrm{pH}$ indicator. spectral changes of 4methylumbelliferone," Analytical Letters, vol. 1, no. 7, pp. 423-428, 1968.

[35] W. Tsuzuki, A. Ue, and Y. Kitamura, "Effect of dimethylsulfoxide on hydrolysis of lipase," Bioscience, Biotechnology, and Biochemistry, vol. 65, no. 9, pp. 2078-2082, 2001.

[36] H. Zhi, J. Wang, S. Wang, and Y. Wei, "Fluorescent properties of hymecromone and fluorimetric analysis of hymecromone in compound Dantong capsule," Journal of Spectroscopy, vol. 2013, Article ID 147128, 9 pages, 2013.

[37] A. Nieter, P. Haase-Aschoff, D. Linke, M. Nimtz, and R. G. Berger, "A halotolerant type A feruloyl esterase from Pleurotus eryngii," Fungal Biology, vol. 118, no. 3, pp. 348-357, 2014.

[38] A. Piscitelli, V. Tarallo, L. Guarino, G. Sannia, L. Birolo, and C. Pezzella, "New lipases by mining of Pleurotus ostreatus genome," PLoS One, vol. 12, no. 9, Article ID e0185377, 2017. 